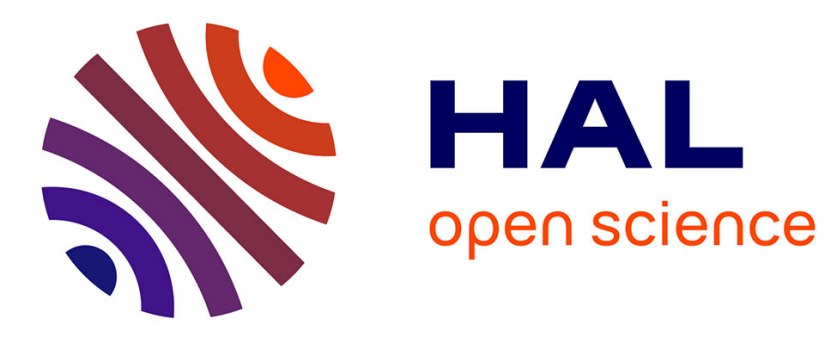

\title{
Interlocked grain and density patterns in Bagassa guianensis: changes with ontogeny and mechanical consequences for trees
}

Julie Bossu, Romain Lehnebach, Stéphane Corn, Arnaud Regazzi, Jacques Beauchêne, Bruno Clair

\section{To cite this version:}

Julie Bossu, Romain Lehnebach, Stéphane Corn, Arnaud Regazzi, Jacques Beauchêne, et al.. Interlocked grain and density patterns in Bagassa guianensis: changes with ontogeny and mechanical consequences for trees. Trees - Structure and Function, 2018, 32 (6), pp.1643-1655. 10.1007/s00468018-1740-x . hal-01850456

\section{HAL Id: hal-01850456 https://hal.science/hal-01850456}

Submitted on 27 Jul 2018

HAL is a multi-disciplinary open access archive for the deposit and dissemination of scientific research documents, whether they are published or not. The documents may come from teaching and research institutions in France or abroad, or from public or private research centers.
L'archive ouverte pluridisciplinaire HAL, est destinée au dépôt et à la diffusion de documents scientifiques de niveau recherche, publiés ou non, émanant des établissements d'enseignement et de recherche français ou étrangers, des laboratoires publics ou privés. 


\title{
Interlocked grain and density patterns in Bagassa guianensis: changes with ontogeny and mechanical consequences for trees
}

\author{
Julie Bossu $^{1} \cdot$ Romain Lehnebach $^{2} \cdot$ Stephane Corn ${ }^{3} \cdot$ Arnaud Regazzi $^{3} \cdot$ Jacques Beauchêne $^{1} \cdot$ Bruno Clair $^{1}$ \\ Julie Bossu \\ juliebossu@hotmail.fr \\ Bruno Clair
bruno.clair@cnrs.fr \\ Romain Lehnebach \\ lehnebach.romain@hotmail.fr \\ Bruno Clair
bruno.clair@cnrs.fr \\ Stephane Corn \\ stephane.corn@mines-ales.fr \\ Arnaud Regazzi \\ arnaud.regazzi@mines-ales.fr \\ Jacques Beauchêne \\ jacques.beauchene@cirad.fr \\ 1 CNRS, UMR EcoFoG, AgroParisTech, Cirad, Inra, \\ Université des Antilles, Université de Guyane, Campus \\ Agronomique, BP 701, 97387 Kourou, France \\ 2 Laboratoire de Mécanique et Génie Civil (LMGC), \\ Université de Montpellier, Place E. Bataillon, \\ 34095 Montpellier, France \\ 3 C2MA, IMT Mines Ales, Université de Montpellier, 6 \\ Avenue de Clavières, 30319 Ales Cedex, France
}

Key message Interlocked grain and basic density increase from pith to bark in Bagassa guianensis and greatly improve trunk torsional stiffness and wood tenacity in the radial plane.

\begin{abstract}
Trees modulate their building material, wood, throughout their lifetime to meet changing mechanical needs. Basic density, a widely studied wood property, has been proved to be negatively correlated to growth rate and is then considered to reflect the diversity of species growth strategies. An alternative way for trees to modulate growth strategy at constant construction cost is changing the organisation of their fibre network. Interlocked grain, the result of a periodic change in the orientation of the fibres in the tangential plane, is found in numerous tropical tree species. In this study, we first describe the variations in basic density and interlocked grain occurring during ontogeny of Bagassa guianensis, a fast-growing Amazo-nian species, and analyse their influence on the local mechanical properties of wood at the tissue level. The observed radial patterns and properties are then incorporated in a finite element model to investigate their effect on mechanical properties of the trunk. We report extreme and highly reproducible concomitant radial variations in basic density and interlocked grain in all the sampled trees, with grain angle variations ranging from $-31^{\circ}$ to $23^{\circ}$. Such changes in wood during ontogeny allows trees to tailor their growth rate while greatly improving resistance to torsion and reducing the risk of splitting.
\end{abstract}

Keywords Interlocked grain $\cdot$ Basic density $\cdot$ Wood radial patterns $\cdot$ Tree architecture $\cdot$ Growth strategy $\cdot$ Biomechanics

\section{Introduction}

In the context of dense tropical forest, trees species develop a large diversity of growth strategies to reach a dominant position within the canopy while guaranteeing trunk load bearing capacities. The purpose-built wood structure produced by the trees is therefore optimised to meet specific requirements needed to compete with surrounding species and adapt to environmental conditions.
For this purpose, wood traits involved in tree biomechanics are continuously adjusted throughout plant development to meet the specific needs created by their growth strategy and environmental conditions (Lachenbruch et al. 2011). Wood tissues keep the memory of tree life history and inte-grate the overall successive modifications that occurred 
from seedling to mature stages. Such variations result in a specific radial gradient of wood properties within the trunk (Lachenbruch et al. 2011) which enables post interpretation of tree development and highlights the species' overall growth strategies.

Among the wood properties giving access to comprehensive elements to investigate tree growth, different authors reported the interest of studying the basic density (BD) radial patterns in trees. Indeed, several studies have demonstrated that BD can vary considerably within the tree (Yao 1970; Whitmore 1973; Fimbel and Sjaastad 1994; Woodcock and Shier 2002; Williamson et al. 2012; Morel et al. 2018) —especially under the tropics (Wiemann and Williamson 1989; Hernandez and Almeida 2003) where such gradients are even more pronounced-and depends to a great extent on growth conditions (McLean et al. 2011). At the inter-specific level, several studies evidenced a negative relationship between growth rate and BD (Arets et al. 2003; Muller-Landau 2004; Falster and Westoby 2005; King et al. 2005). At the intra-individual level, this relation is also relevant: the production of low-density wood (i.e. low construction cost) during early development stages enables rapid height growth. When a tree reaches the canopy, height growth levels off and the production of higher density wood starts (i.e. high construction cost). The later production of high-density wood is seen as a biomechanical adaptation to resist wind-induced stresses (Woodcock and Shier 2002). High BD is hypothesised to be responsible for the balance between mechanics and metabolic cost by achieving high mechanical strength with a reduced volume of wood, which, in turn limits respiration cost compared to low-density wood (Larjavaara and Muller-Landau 2010). Finally, BD is also considered as a critical parameter in tree buckling (McLean et al. 2011; Fournier et al. 2013). For the reasons here mentioned, BD radial gradient is considered to be a key parameter in controlling tree growth throughout its development and have also been shown to have biomechanical advantages.

An alternative way to optimise tree mechanical design at constant construction costs is modifying the organisation of the fibre network. For example, the angle of the cellulose microfibrils inside the wood fibre cell wall can vary through ontogeny from high value in juvenile wood (enabling compliant fibres), to low value in mature wood (associated with stiffer fibres) (Li et al. 2011). Such modifications may modify trunk flexibility to adapt to environmental conditions (Barnett and Bonham 2004). Another mechanism produces a similar effect in the tree at a larger scale: the orientation of wood fibres can be aligned along the trunk axis or inclined. In the second case, there may be small variations in the grain angle in the radial plane (wavy grain), increasing grain angle in the tangential plane from pith to bark (spiral grain), or periodic changes in the orientation of the fibres from the $\mathrm{Z}$ to $\mathrm{S}$ helix in the tangential plane (interlocked grain) (IG) (Hejnowicz and Romberger 1979; Krawczyszyn and Romberger 1979; Włoch et al. 2009; Cabrolier 2009). The latter conformation is observable in numerous temperate and tropical tree species (Hernandez and Almeida 2003; Thinley et al. 2005; Slater and Ennos 2015; Özden et al. 2017). According to Kribs (1950, cited by Hernandez and Almeida (2003)), $75 \%$ of the 258 tropical trees they analysed showed IG. Arostegui (1982) also found that 33 out of 60 Peruvian tropical hardwoods they tested had this feature. Nevertheless, only a few studies suggested a potential functional benefit of IG. Webb (1969), supported by Détienne (1979), proposed that IG could improve water distribution from the roots to the crown. However, as the inclination of fibres is known to reduce wood stiffness at local scale (Cabrolier 2009; Brémaud et al. 2010), a possible role in mechanics was not taken into consideration.

The objective of the present study is to explore the mechanical role of IG in the whole stem in relation with variations in BD in Bagassa guianensis Aubl., a high growth rate and long life Amazonian species, known to develop both pronounced IG and large BD radial gradients (Cabrolier 2009; Bossu et al. 2016). This species is a suitable model to investigate the simultaneous effects of variations in IG and $\mathrm{BD}$ on trunk biomechanics. Moreover, its specific development ensuring both competitive growth and trunk longevity is an unusual and effective strategy that merits investigation.

The specific aims of the present work are (1) to characterise the changes in BD and IG in relation with the tree development stages in B. guianensis, (2) to measure the effects of such variations on local mechanical properties, and (3) to incorporate the results in a biomechanical model including both changes in fibre orientation and density to determine their combined effect on the elastic properties of the living trunk. Finally, the contribution of BD and IG variations to the species growth strategy and trunk biomechanics are discussed.

\section{Materials and methods}

\section{Tree description}

Eleven Bagassa guianensis Aubl. (commercially known as Tatajuba) trees were sampled near the Paracou experimental station $\left(5^{\circ} 19^{\prime} \mathrm{N} ; 52^{\circ} 56^{\prime} \mathrm{W}\right)$ in French Guiana, on the edge of a secondary forest along a trail opened almost 30 years ago. Specimens were chosen to cover a homogeneous distribution of diameters at breast height (DBH), ranging from 13 to $55 \mathrm{~cm}$. Tree volumes were estimated by measuring successive stem segments, where one segment comprises the bole and the other the crown. Each segment was characterised by its length and both initial and final diameter. Volumes of the trunk and crown axis were calculated by adding the volumes of each segment considering them as successive cones. Like 
in most tree species, the crown of B. guianensis develops through a reiterative process duplicating the architectural unit (i.e. the fundamental set of axis categories inherent to the species) (Barthelemy and Caraglio 2007). Thus, the architectural stage of development (ASD) indicator (Nicolini et al. 2012) was used, allowing the characterisation of the ontogenetic stage through structural features.

ASD 1 is defined by the presence of sequential branches born by the trunk and the absence of a fork; ASD 2 by the presence of both a young fork and sequential branches; ASD 3 represents a mature stage in which the fork is well established with ramified branches and the bole is pruned.

\section{Sampling}

Radial planks around $30 \mathrm{~cm}$ in length were sampled at breast height on each tree, taking care to avoid defects and singularities. Planks were first planed to a thickness of $3 \mathrm{~cm}$, marked to respect the same orientation during cutting and then sawed into three parts, respectively, 2, 15 and $3 \mathrm{~cm}$ in length. The top $2 \mathrm{~cm}$ part was planed to a thickness of $2 \mathrm{~cm}$ and split with a knife every $0.5 \mathrm{~cm}$ along the radial axis. The split samples were used to measure BD and grain angle. The $15 \mathrm{~cm}$ middle part was planned to a thickness of $1 \mathrm{~cm}$, air dried and sawed every $0.2 \mathrm{~cm}$ along the radial axis to produce the elongated samples for modulus of elasticity (MOE) and microfibril angle measurements. Finally, the $3 \mathrm{~cm}$ bottom part was sawed at $4 \mathrm{~cm}$ intervals along the radial axis and air dried to produce samples for the measurement of tenacity and interlocked grain.

\section{Wood properties}

\section{Basic density (BD)}

Basic density was measured on small samples $\left(R \times T \times L=0.5 \times 2 \times 2 \mathrm{~cm}^{3}\right)$. BD was defined as the ratio between dry mass (M0\%) and saturated volume (VSat): $\mathrm{BD}=\mathrm{M} 0 \% / \mathrm{VSat}$ (Kollmann and Côté 1968). Sample volume (VSat) was calculated using the Archimedes principle on a Sartorius CP224S balance (precision: $0.2 \mathrm{mg}$ ) as described in Bossu et al. (2016). Dry mass was measured on the same balance after 3 days of stabilisation at $103^{\circ} \mathrm{C}$.

\section{Interlocked grain (IG)}

Interlocked grain was assessed using two different methods. Each of these methods performed the measurements on the same samples as those scaled to fit to BD and tenacity analysis. On the BD samples, grain angle deviation in relation to the trunk was evaluated with a goniometer by visual assessment on the tangential-longitudinal plane of each sample. From the photographs of split tenacity samples, an interlocked grain index (IGIndex) was calculated with ImageJ software (Schneider et al. 2012) to characterise each sample, given by the ratio of the surface deviation due to inclined grain to the radial dimension (respectively, $S$ and $R$ ) (Fig. 1c, d). For more clarity, when referring to the variations in the grain angle from pith to bark and maximum amplitudes from negative to positive angles in IG samples, the terms "IG variations" and "IG amplitudes" respectively, are used hereafter.

\section{Microfibril angle}

Microfibril angles were measured using X-ray diffraction (XRD) on a 4-circle diffractometer (Gemini, Agilent Technologies, Santa Clara, USA) following the procedure described in Montero et al. (2012). The average microfibril angle of each sample was estimated using the "improved Cave's method' (Yamamoto et al. 2001) which is more accurate when the angle is below $25^{\circ}$, which is the case for B. guianensis.

\section{Wood mechanical properties}

\section{Modulus of elasticity (MOE)}

MOE was measured on the elongated air-dry samples $\left(R \times T \times L=0.2 \times 1 \times 15 \mathrm{~cm}^{3}\right)$ after stabilisation in controlled conditions $\left(23 \pm 1{ }^{\circ} \mathrm{C}\right.$ and $\left.60 \pm 2 \% \mathrm{RH}\right)$. Tests were performed using non-contact forced vibrations of free-free bars. Specimens were supported by loose thin silk threads located at the nodes of the 1 st mode of flexural vibrations. Vibrations were applied with an electro-magnet facing a thin iron plate glued to one end of the specimen and the displacement was measured at a vibration anti-node by a non-contact laser sensor. A frequency scan allowed detection of the first resonant frequency (in bending) from which the modulus of elasticity (MOE) was deduced according to the Euler-Bernouilli equation (Brémaud et al. 2012).

\section{Tenacity}

The purpose of this test is to reproduce cracks that might occur at the place of the fork when the two main axes of the crown undergo opposite charge loadings. To this end, the following experimental setup was designed in order to study if interlocked grain can limit the risk of trunk splitting at the place of the fork. In the $3 \mathrm{~cm}$ bottom part of radial planks, successive samples were produced from bark to bark along the radial direction $\left(R \times T \times L=4 \times 3 \times 3 \mathrm{~cm}^{3}\right)$, as illustrated in Fig. 1a. The specific length of $4 \mathrm{~cm}$ in the $R$ direction has been chosen in order to include a complete period of interlocked grain (the pattern being reproducible every $4 \mathrm{~cm}$ ). Tenacity was measured on each of the samples, characterized 


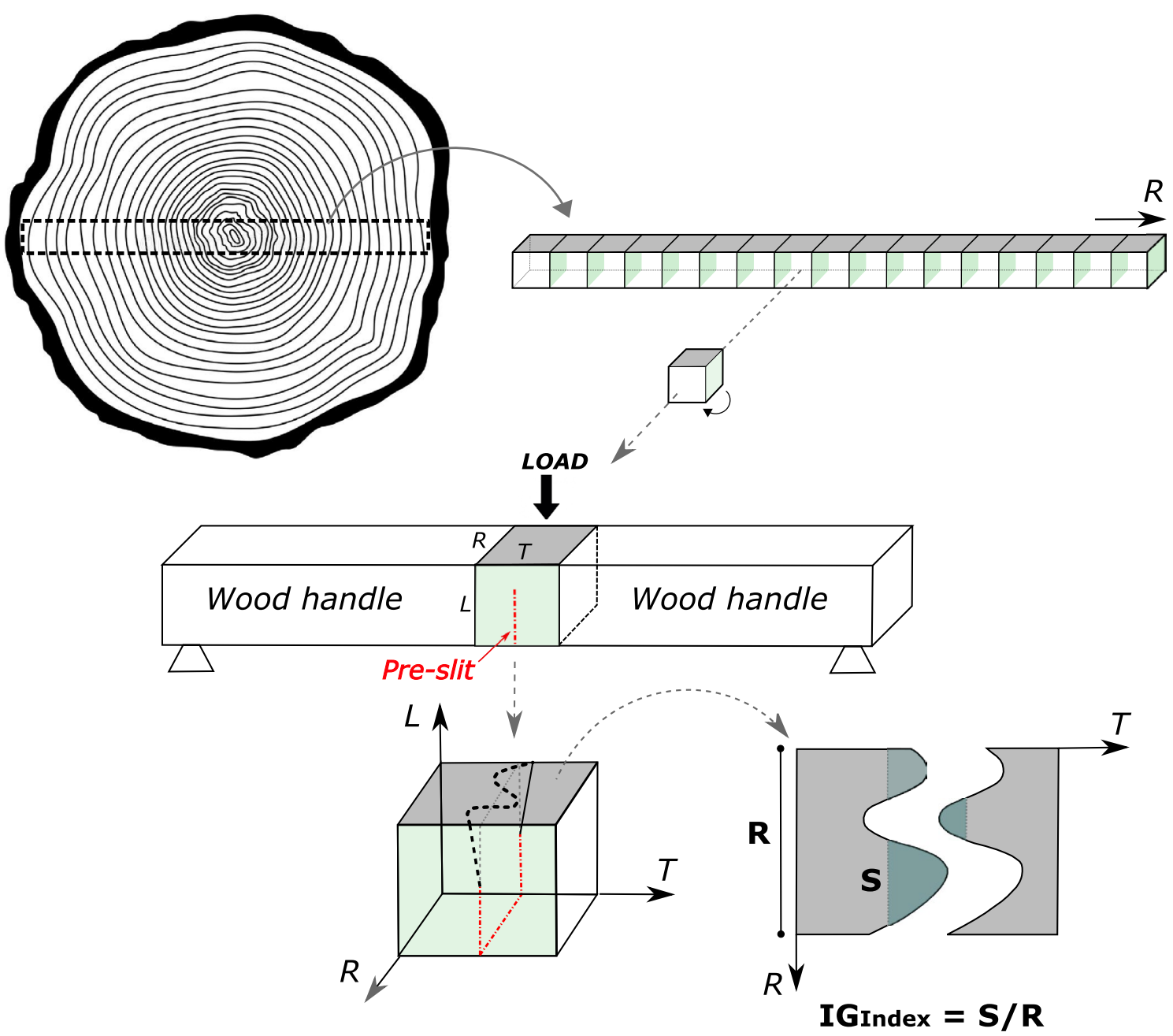

Fig. 1 Tenacity test and measurement of the interlocked grain index (IGIndex) on split samples. a cutting of the radial bar; $\mathbf{b}$ experimental set up for fracture energy testing; $\mathbf{c}$ observation of the crack propaga-

by varying IG amplitudes, following the method described in Hernandez and Almeida (2003). The cubic samples were first glued on their RL faces to wood handles (Peltogyne $s p$., density $=0.87)\left(R \times T \times L=10 \times 4 \times 3 \mathrm{~cm}^{3}\right)$ using polyurethane glue and under press loading during $24 \mathrm{~h}$. Then, a $1.6 \mathrm{~cm}$ pre-slit was sawn in the middle of the sample, as illustrated in Fig. 1b. The fracture energy, i.e. the energy necessary to split the sample in the TL fracture plan (Ashby et al. 1985) ${ }^{1}$, was measured using a strength piloted 3-points flexion test. On a sub-sample, tenacity tests were performed in both saturated and air-dry conditions and revealed that

\footnotetext{
${ }^{1}$ In this work, the fracture system will always be characterised by two letters accordingly to Ashby et al. (1985): here for example the first letter "tangential" indicating the direction normal to the crack plane and the second letter "longitudinal" referring to the direction of crack propagation.
}

tion from the pre-slit; $\mathbf{d}$ characterisation of the resulting crack profile and calculus of $\mathrm{IG}_{\text {Index }}$ (illustrations adapted from Hernandez and Almeida 2003)

moisture content had a minor impact on tenacity measurement (mean difference of $-2.04 \%$ from green to air-dry conditions; non-significant according to Kruskal-Wallis test: $\mathrm{pv}=0.954)$.

\section{Modelling of trunk biomechanical behavior}

\section{Description of the model trunks}

The influences of BD variations, IG variations and their combined effects on tree biomechanical behaviour were evaluated through finite element analysis. Six different trunks were modelled as cylinders with a radius $R=20 \mathrm{~cm}$ and a unitary length $l=1 \mathrm{~m}$. Each trunk was characterised by three different radial patterns of fibre orientation (axial grain, spiral grain or IG) and two radial patterns of $\mathrm{BD}$ (constant $\mathrm{BD}$ or $\mathrm{BD}=f(r))$. 


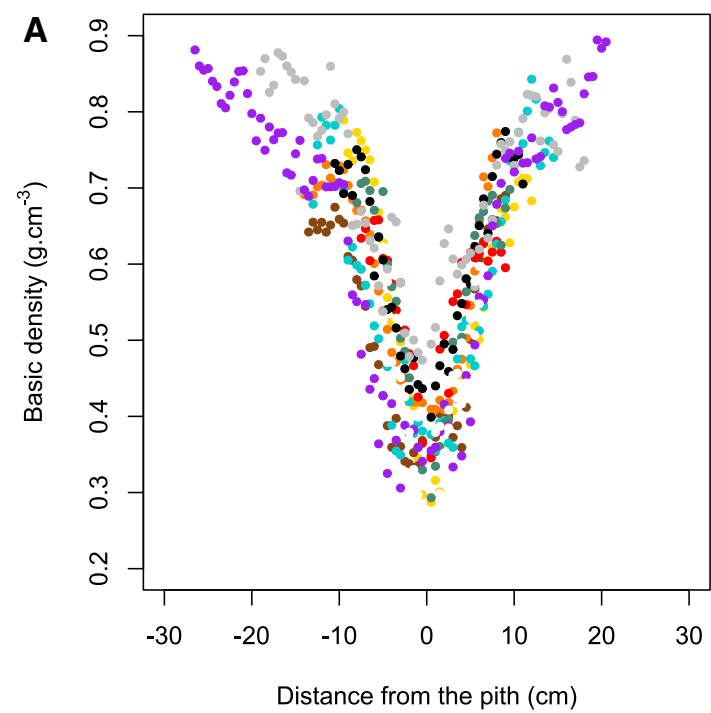

Fig. 2 a Variations in basic density (BD) with distance from the pith. Each individual is represented by one colour. b Variations in basic density (BD) with absolute distance from the pith. The solid line cor-

\section{Variations of the parameters}

$B D=f(r)$ Parameters were adjusted based on the average radial variations measured on the 11 trees (see "Results").

$B D=$ constant $\mathrm{A}$ constant value BDeq was chosen to correspond to an equivalent construction cost like in the variable BD model. BDeq was thus calculated by integrating the $\mathrm{BD}$ variation along the radius in order to have an identical mass of the trunk model, leading to the following formula: $\mathrm{BDeq}=\frac{2}{R^{2}} \int_{0}^{R} r \cdot \mathrm{BD}(r) \mathrm{d} r$, where $r$ is the current radial coordinate in the cylindrical coordinates system of the trunk model.

Axial grain the grain angle was considered as null.

Spiral grain the grain angle (GA) (in degrees) was set as proportional to the radial coordinate $r$ (in $\mathrm{cm}$ ) such that $\mathrm{GA}=r$ (with $\mathrm{GA}=0-20^{\circ}$ when $r=0$ to $20 \mathrm{~cm}$ ).

Interlocked grain $\mathrm{GA}=f(r)$ is a sinusoidal function adjusted based on the average radial variations obtained from the analysis of the wood traits (see "Results").

\section{Mechanical simulations}

Finite element simulations were performed using Comsol Multiphysics ${ }^{\circledR}$ software to compare the axial compressive, transverse flexural and axial torsional stiffness of each model. The material behaviour was assumed to be elastic and transversely isotropic along the fibre direction. The modulus of elasticity (MOE) in the fibres direction was set according to the experimental results discussed below. The other elastic coefficients such as transverse modulus, shear modulus and Poisson's ratios were adjusted according to

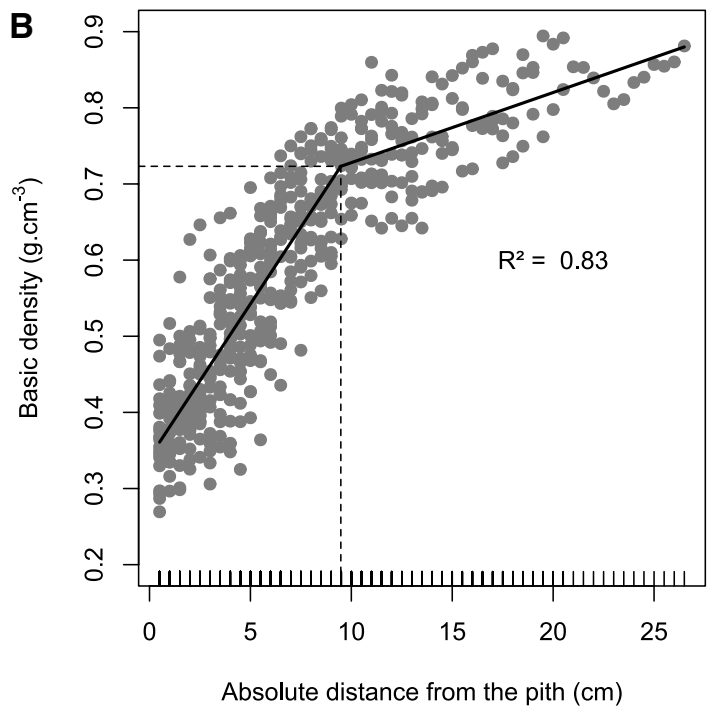

responds to the piecewise linear model emphasizing a change in slope (rupture point) at $9.48 \mathrm{~cm}$ from the pith for $\mathrm{BD}=0.72$ (dashed lines)

the experimental relations proposed by Guitard (1987). The variations of grain angle within the trunk led to an orthotropic finite element model. Three load cases were simulated for each model: compression, flexion and torsion. A unitary displacement or rotation was applied in the corresponding direction. The reaction force was evaluated for each load case, thus making it possible to estimate the apparent stiffnesses of the structure. All the calculations involved static analyses and small strain assumption. A mesh convergence study was carried out, which led to a 200,300 elements model.

\section{Results}

\section{Radial variations in wood properties in the trunk}

\section{Basic density (BD)}

In all individuals, BD was characterised by a major increase from pith to bark, ranging from 0.27 to $0.89 \mathrm{~g} \mathrm{~cm}^{-3}$. Figure $2 \mathrm{a}$ shows the BD radial profiles at breast height of the 11 trunks showing a radial increase in BD in all the trees. A rupture point in the average BD increasing curve is graphically observable in all individuals with a diameter greater than $20 \mathrm{~cm}$ (Fig. 2b). Thus, BD was better predicted by a model accommodating a changing slope at a radial position of $9.48 \mathrm{~cm}\left(\mathrm{AICc}=-1325.9, R^{2}=0.83\right.$ ) than by a simple linear model $\left(\mathrm{AICc}=-1109.23, R^{2}=0.73\right.$, $\left.\mathrm{pv}<0.001\right)$.

During the first phase, BD increased with a slope of $4.03 \mathrm{~g} \mathrm{~cm}^{-3} \mathrm{~m}^{-1}$, whereas in the second phase (passing the 


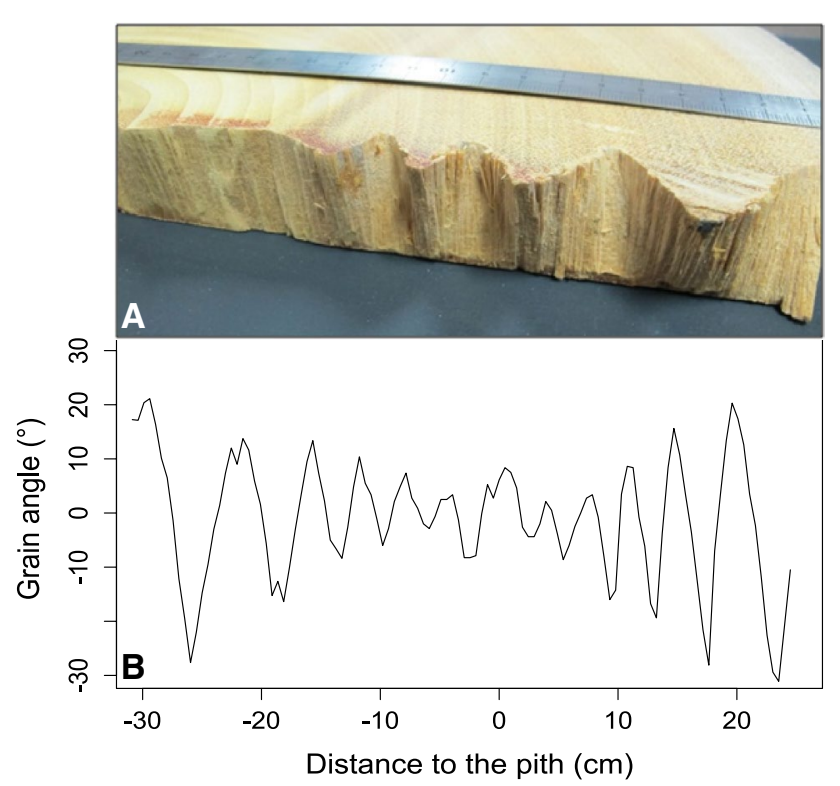

Fig. 3 a Observation of IG variations in a radial disk sampled at breast height in a mature tree of Bagassa guianensis. b Corresponding IG variations over the radial profile measured with goniometer. IG amplitudes increase with distance from the pith and the number of periods is equal on each side of the pith. The half-period is defined as the time lapse between two successive peaks

rupture point), the slope was reduced to $0.92 \mathrm{~g} \mathrm{~cm}^{-3} \mathrm{~m}^{-1}$. The change in $\mathrm{BD}$ is then accurately described as two linear functions of radial position $(r)$, as follows:

1. for $r \leq 9.48 \mathrm{~cm}: \mathrm{BD}=0.34+0.04 \times|r|$

2. for $r \geq 9.48 \mathrm{~cm}: \mathrm{BD}=0.64+0.01 \times|r|$

\section{Interlocked grain (IG)}

Each of the 11 trees had interlocked grain (IG), i.e. fibre orientation periodically changed from $\mathrm{Z}$ to $\mathrm{S}$ helix with diameter, with a similar radial pattern: from pith to bark, grain angle variations followed a sinusoidal trend (Fig. 3a). Samples showed very low IG amplitudes near the pith, increasing toward the bark. Figure $3 \mathrm{~b}$ shows the IG variations observed in the biggest tree in the sample, ranging from $-31^{\circ}$ to $23^{\circ}$. Smaller trees showed a narrower range but with a similar trend.

For all trees, the parameters of the sinusoidal variations varied identically from pith to bark. The half-period did not vary significantly along the radial profile, i.e. it remained constant irrespective to the number of the halfperiod $(\mathrm{pv}=0.251)($ See Supplementary Material 1A), despite observable higher variability near the pith. For all individuals, grain angle periods were characterised by an average half period of $1.75 \mathrm{~cm}$. Maximum IG amplitudes (absolute successive peak amplitudes, where each peak corresponds to a half period) increased linearly with radial position $\left(R^{2}=0.54\right.$; pv $\left.<2.2 \mathrm{e}-16\right)$ (cf. Supplementary Material 1B). Therefore, grain angle (GA) can be approximated by a sinusoidal law of linearly increasing magnitude according to radial position $r$, which can be expressed as: $\mathrm{GA}=r \times \sin ($ Half period $\times r)$, with Half period $=1.75 \mathrm{~cm}$.

\section{Microfibril angle}

In contrast to IG, microfibril angle remained constant in mature wood, with little variation around $11.6^{\circ}$ as mean value (variance of $3.6^{\circ}$ obtained with 548 measured samples). Microfibril angle was higher $\left(20^{\circ}\right)$ in the first $5 \mathrm{~cm}$ around the pith.

\section{Effect of BD and GA on wood mechanical properties}

\section{Modulus of elasticity (MOE)}

The relationship between MOE and BD is not linear over the radial profile because of the influence of grain angle deviation on longitudinal MOE values. In Fig. 4a, it can be observed that when samples have only straight fibres $\left(-5^{\circ} \leq \mathrm{GA} \leq 5^{\circ}\right)$ (filled circles in Fig. $4 \mathrm{a}$ ), MOE is maximum and increases linearly with BD. For this subsampling, the relationship between MOE and BD can be expressed as following:

$\mathrm{MOE}=2.861+22.158 \times \mathrm{BD}\left(R^{2}=0.52, \mathrm{pv}<0.001\right)$

Further from the pith, for BD higher than $0.65 \mathrm{~g} \mathrm{~cm}^{-3}$, fibres are more and more out of the axis of the sample (largest circles in Fig. 4a) and MOE decreases drastically. Here, MOE variability is high, ranging from 6 to $27 \mathrm{GPa}$. The effect of high grain angle on MOE is illustrated on Fig. 4b: this representation highlights the negative relationship existing between MOE and GA in samples with $\mathrm{BD}>0.65 \mathrm{~g} \mathrm{~cm}^{-3}\left(\mathrm{MOE}=19.9-0.44 \times|\mathrm{GA}|, R^{2}=0.46\right.$, pv <0.001) (Fig. 4b).

\section{Tenacity}

When evaluating the effect of density on fracture energy, a significant relationship ( $\mathrm{pv}<0.001$ ) was detected. However, this relation was mainly due to a leverage effect caused by two outlier values with BD lower than $0.55 \mathrm{~g} \mathrm{~cm}^{-3}$. After removal of these observations, the relationship was no longer significant $\left(R^{2}=0.06, \mathrm{pv}=0.043\right)$. On the contrary, fracture energy measurements in tenacity tests revealed a positive relationship with IGindex $\left(R^{2}=0.42\right.$, pv $\left.<0.001\right)$ (Fig. 5). 


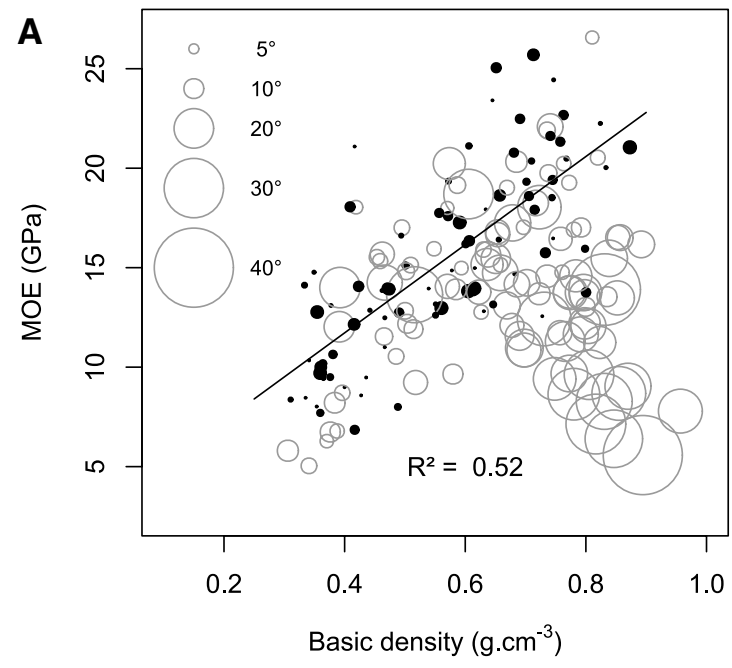

Fig. 4 a Variations of the modulus of elasticity (MOE) with basic density (BD). The diameter of the points or circles corresponds to a specific range of GA accordingly to the chart in the top-left corner. The filled circles correspond to samples characterised by the lowest

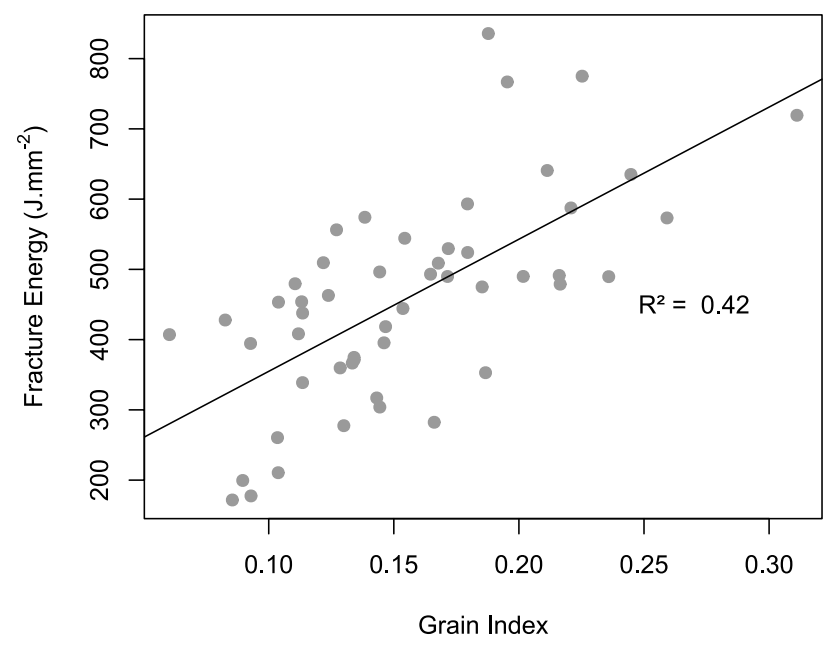

Fig. 5 Fracture energy from tenacity test as a function of IGindex measured on split samples

\section{Modelling of the influence of BD and IG radial variations on trunk mechanical properties}

Despite some disparities between individuals, reproducible patterns of BD, MOE and IG were observed. Such observations enable the construction of reliable trunk models to study the mechanical properties of the B. guianensis tree.

The radial patterns measured for BD and IG were implemented in the settings of the different model trunks and compared to the "axial grain and constant BD" model as a reference. The value used for the equivalent constant basic density for identical tree construction costs (BDeq) according to Eq. 1 was computed as 0.736 . The equivalent MOE

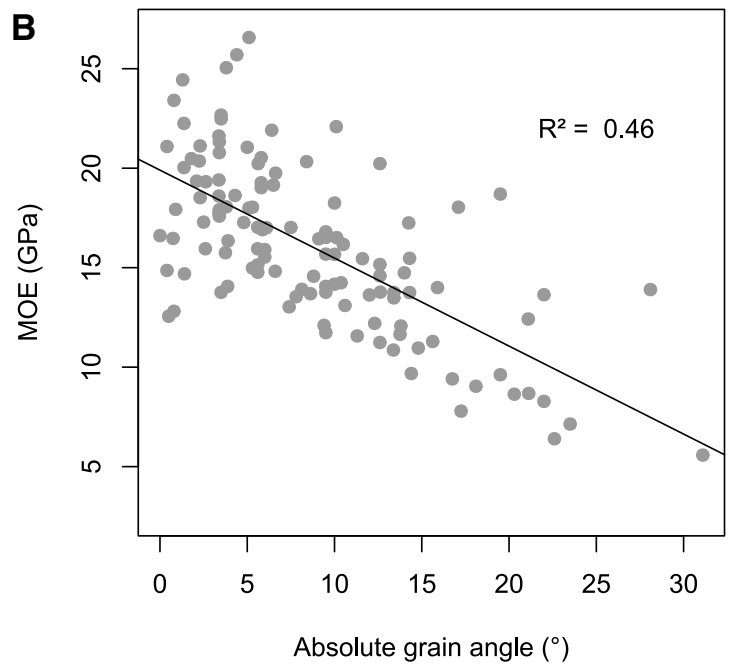

grain angle variations, i.e. $-5^{\circ} \leq \mathrm{GA} \leq 5^{\circ}$. The black solid line represents the relationship between MOE and BD for this specific subsampling. b Relationship between MOE and $|\mathrm{GA}|$ for the sub-sampling with $\mathrm{BD}>0.65 \mathrm{~g} . \mathrm{cm}^{-3}$

Table 1 Details of the models of IG and BD variations within the radial profile used for finite element modelling

\begin{tabular}{ll}
\hline Radial patterns & $\begin{array}{l}\text { Corresponding model used for } \\
\text { numerical analysis }\end{array}$ \\
\hline Axial grain & Grain angle $=0^{\circ}$ \\
Spiral grain & Grain angle $=\mathrm{r}$ \\
Interlocked grain & Grain angle $=r \cdot \sin (1.75 \times r)$ \\
Variable BD & If $r \leq 9.48, \mathrm{BD}=0.34+0.04 \times r$ \\
& If $r \geq 9.48, \mathrm{BD}=0.64+0.01 \times r$ \\
& $\mathrm{MOE}=2.86+22.158 \times \mathrm{BD}$ \\
Constant BD & $\mathrm{BDeq}=0.736$ \\
& MOEeq $=19.17 \mathrm{GPa}$ \\
\hline
\end{tabular}

(MOEeq), calculated from BDeq according to Eq. 2, was computed as $19.17 \mathrm{GPa}$. The different parameters used for numerical modelling are summarised in Table 1. Figure 6 illustrates the geometry of the simulated trunk corresponding to the IG model.

Table 2 summarises the results of numerical simulations performed to assess the effect on trunk stiffness of variations in $\mathrm{BD}$, grain angle (axial grain, spiral grain and IG) and their combination.

In the case of axial grain, as expected, $\mathrm{BD}$ variations had no effect on compressive stiffness but increased flexural stiffness by $3 \%$ and torsional stiffness by $5 \%$.

For constant BD, compared to the axial model, spiral grain caused a strong increase in torsional stiffness $(+25 \%)$ but a decrease in compressive and flexural stiffnesses $(-34$ and $-24 \%$, respectively). IG led to an even more significant improvement of torsional stiffness $(+33 \%)$. But, unlike spiral grain, IG only slightly decreased compressive and 


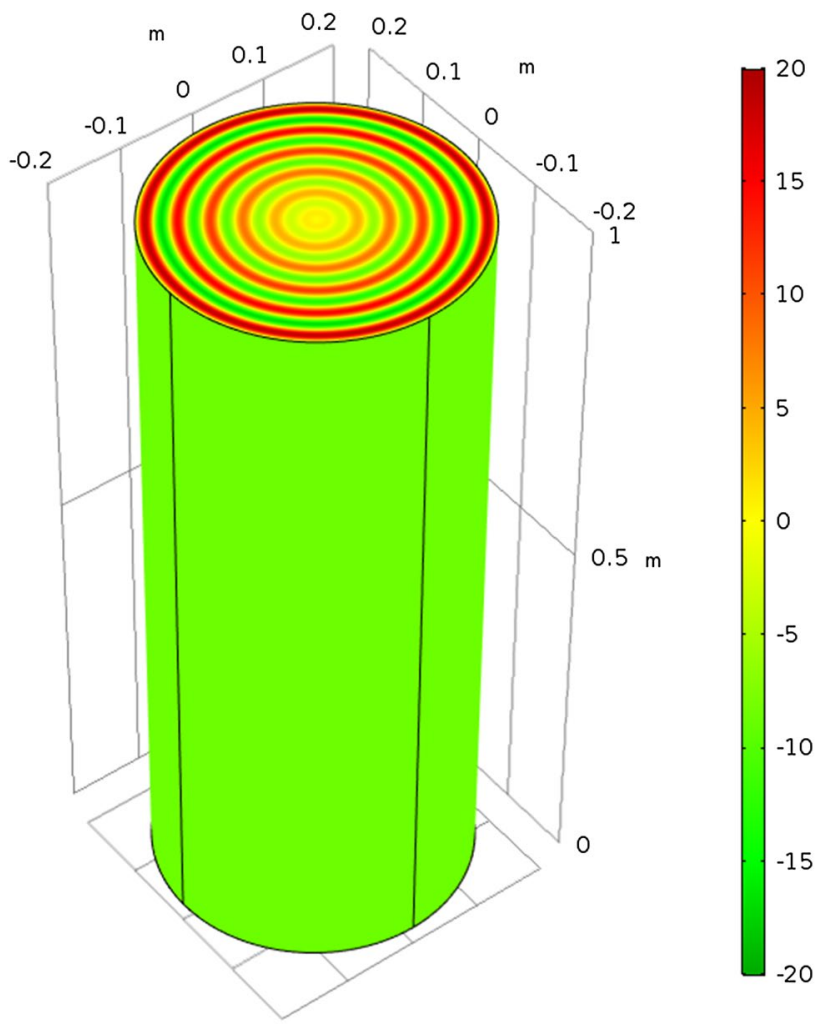

Fig. 6 Example of a finite element model trunk in the case of an interlocked grain pattern. Colour levels indicate grain angles ranging from $-20^{\circ}$ (green) to $+20^{\circ}$ (red) flexural stiffnesses ( -6 and $-2 \%$, respectively). For both constant and variable BD, IG always led to greater torsional stiffness than spiral grain.

Grain angle influenced trunk stiffnesses more significantly than variations in BD. Indeed, the results of the combination of variable $\mathrm{BD}$ and variable grain angle were quite similar to those obtained by combining constant BD and variable grain angle. The models implemented show that a trunk with variable $\mathrm{BD}$ and IG ensures the highest torsional stiffness (140\%) while maintaining most of the compressive and flexural stiffnesses.

\section{Tree development and ontogenetic changes in BD and GA}

Figure 7 illustrates the development of B. guianensis with regard to the above-mentioned variations in wood properties, through the example of the different radial patterns observed in the biggest individual tree in our sample. The description of tree structure according to ASDs indicates that crown development has not yet started in trees with DBH lower than $20 \mathrm{~cm}$. At this stage, the tree structure is characterised by an orthotropic trunk bearing several sequential branches (Fig. 7a, ASD1) and tree height growth results from the elongation of the trunk (Fig. 7b). The wood produced by trees in the ASD1 stage is of relatively high microfibril angle (around $20^{\circ}$ ) and low BD, which respectively, decreases and
Table 2 Details of the parameters used for the numerical simulations of the trunk models and their effect on computed stiffness in compression, flexion and torsion

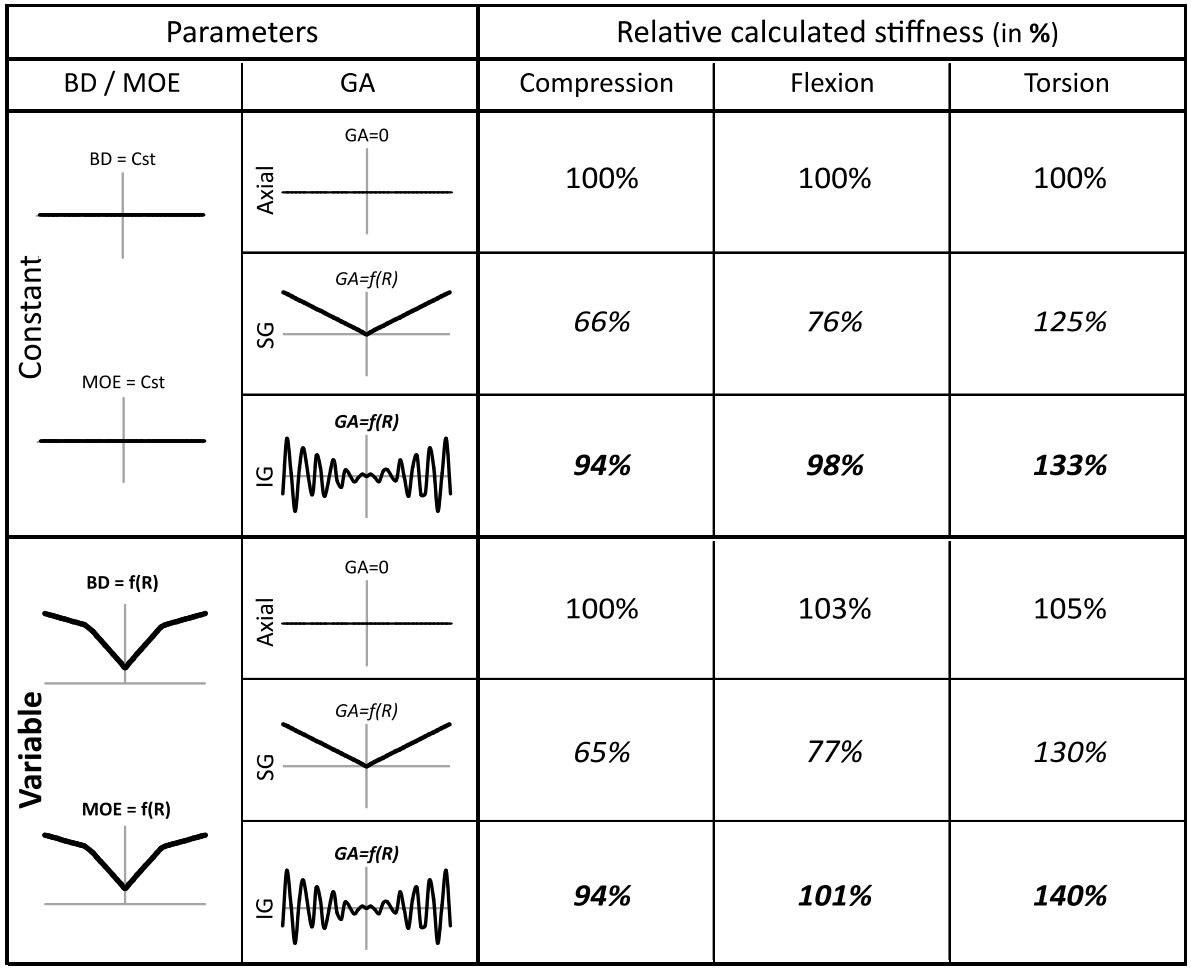

Relative values are presented (where "constant $\mathrm{BD}$ and axial grain" model is the reference, i.e. stands as the $100 \%$ value) 
A
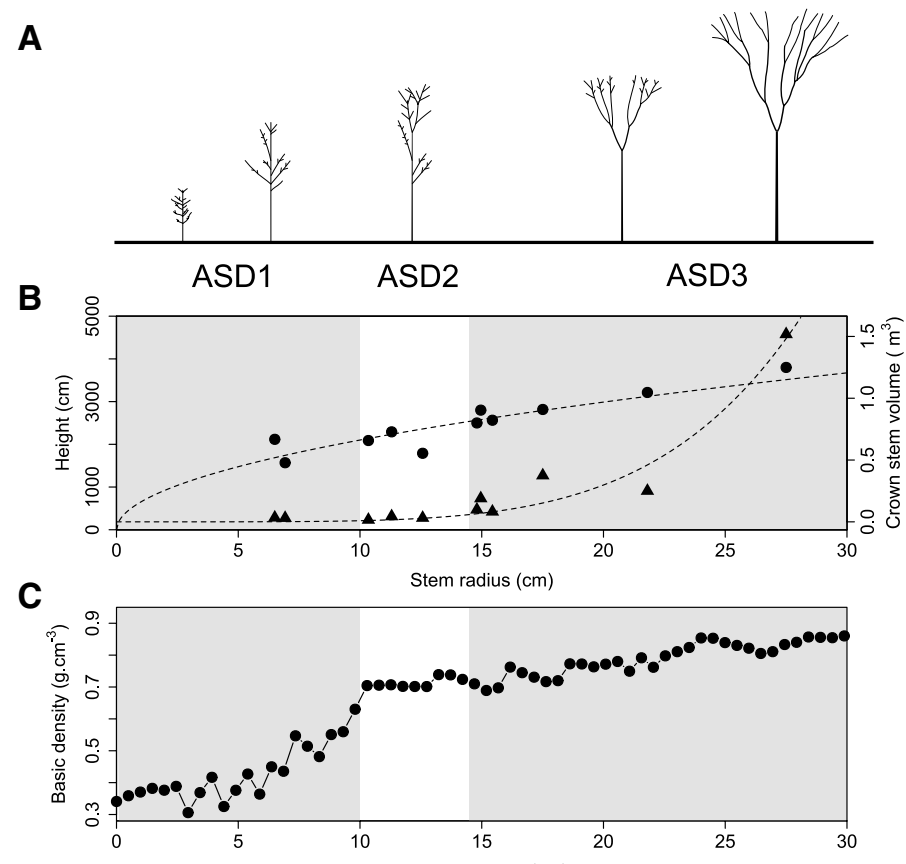

D
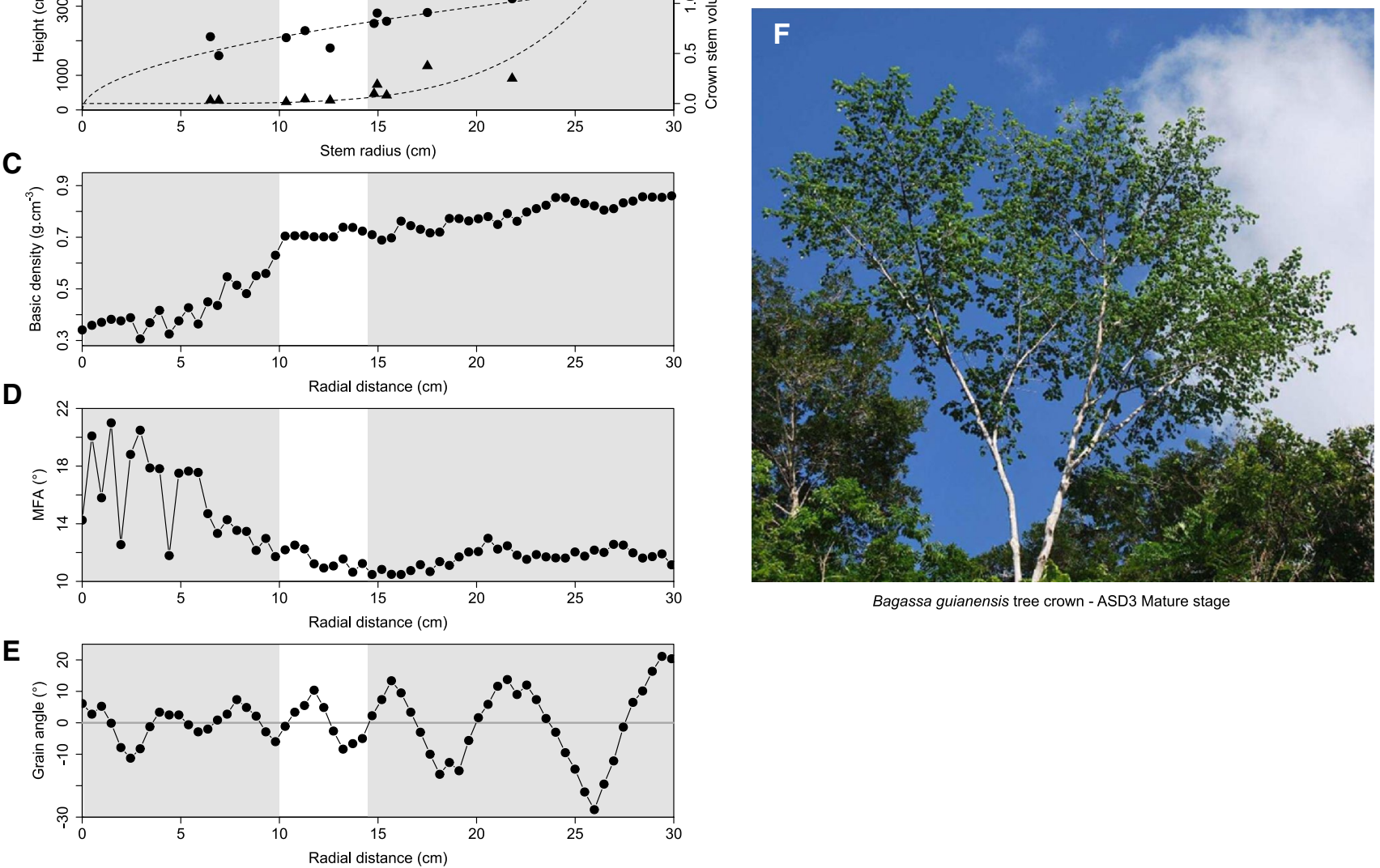

Bagassa guianensis tree crown - ASD3 Mature stage

Fig. 7 Tree development and radial changes in wood properties along the different Architectural Stages of Development (ASD). a Schematic drawings of Bagassa guianensis development based on previous observations of tree architecture (Caraglio, unpublished) and measurements made in this study. b Tree height (circles) and crown stem volume (triangles) as a function of stem radius, regression were

increases dramatically with an increase in radial distance (Fig. $7 \mathrm{c}, \mathrm{d}$ ), whereas variations in the grain angle remain low (Fig. 7e).

Conspicuous forks, i.e. the morphological marker of crown development, were observed in trees with DBH higher than $20 \mathrm{~cm}$. At this stage, tree height growth results from the height growth of the first reiterated branches departing from the fork (Fig. 7b), whereas a few sequential branches remain present along the trunk (Fig. 7a, ASD2). Interestingly, the lowest value of DBH at breast height recorded in ASD2 trees $(20 \mathrm{~cm})$ corresponded approximately to the radial fitted over $\mathrm{DBH}$, and graphed over the stem radius (i.e. $\mathrm{DBH} / 2$ ) for convenience with the other graphs. c-e represent, respectively, the radial variations of basic density (BD), microfibril angle (MFA) and Grain angle within the largest tree sampled. f Illustration of the typical "Y"-like crown shape of Bagassa guianensis trees, built around two long opposite axes

distance value $(9.48 \mathrm{~cm})$ after which the rate of increase of BD slowed down (Fig. 7c). In parallel, the decrease in microfibril angle also slowed down and stabilised around a radial position of $15 \mathrm{~cm}$ (Fig. 7d). During ASD2 development, we also observed the onset of the increase in IG amplitude (Fig. 7e).

The final stage (ASD3) is reached when the DBH increases until around $30 \mathrm{~cm}$ (Fig. 7b). In ASD3, the sequential branches have been shed, tree height continues to increase but the crown also expands laterally due to the development of new forks and new reiterated branches 
(Fig. 7a). Crown expansion is highlighted by a drastic increase in crown stem volume after $15 \mathrm{~cm}$ of stem radius (Fig. 7b). Both the number of reiterated branches and crown stem volume are highly correlated (Pearson correlation, $\rho=0.99, \mathrm{pv}<0.001)$ and can be considered as indicators of crown expansion. At this stage, the mature crown of B. guianensis organized around two main opposite axes and funnel shaped, i.e. the crown is widest at the top, and the fork is approximately located at mid-height of the tree, as illustrated in Fig. 7f. During this final stage of development, microfibril angle shows almost no variation and remains constant at a low value (around $12^{\circ}$ ). Finally, in ASD3 trees, IG amplitude continues to increase (Fig. 7e) as well as BD, which increases at the same rate as trees in ASD2 stage (Fig. 7c).

\section{Discussion}

\section{Variations in basic density (BD) within the tree}

Strong radial variations in BD were observed in all the trees. Ontogenetical variations in BD have already been reported in numerous tropical tree species (Wiemann and Williamson 1989; Omolodun et al. 1991; Hernandez and Restrepo 1995; Parolin 2002; Woodcock and Shier 2002; Hietz et al. 2013; Morel et al. 2017). An interspecific survey of radial changes in $\mathrm{BD}$ in the neotropics highlighted a negative relationship between radial changes in $\mathrm{BD}$ and $\mathrm{BD}$ at the centre of the stem (Hietz et al. 2013), in other words, species producing low density wood in the juvenile phase exhibit high radial variations. This result agrees with Wiemann and Williamson (1988) who reported an extreme increase in radial BD in tropical pioneers, ranging between 0.7 and $1.0 \mathrm{~g} \mathrm{~cm}^{-3} \mathrm{~m}^{-1}$ and very low BD at the stem centre $\left(0.09-0.17 \mathrm{~g} \mathrm{~cm}^{-3}\right)$. More recently, Morel et al. (2018) documented a radial increase of $1.1 \mathrm{~g} \mathrm{~cm}^{-3} \mathrm{~m}^{-1}$ in BD, with a BD of $0.3 \mathrm{~g} \mathrm{~cm}^{-3}$ at the stem centre of Parkia velutina, an emergent heliophilic species in French Guiana. These generally acknowledged extreme radial changes of BD are however lower than the change observed in B. guianensis. Indeed, here we report an overall gradient of $1.8 \mathrm{~g} \mathrm{~cm}^{-3} \mathrm{~m}^{-1}$ in $B$. guianensis, a very high gradient for a species producing a BD of $0.35 \mathrm{~g} \mathrm{~cm}^{-3}$ in the juvenile phase.

Such a strong positive gradient of BD from pith to bark is commonly considered as a distinctive feature of fast-growing species (i.e. heliophilic species) (Woodcock and Shier 2002; Hietz et al. 2013; Osazuwa-Peters et al. 2014).

Indeed, the low-density wood observed near the pith (i.e. low construction cost) might enable a rapid increase in diameter at a given construction cost, thereby enabling rapid height growth in the juvenile stage. Later, when the tree reaches the canopy and the crown develops, tree self-weight and crown surface exposed to wind increase the mechanical stresses applied to the stem. This change in the mechanical environment is accompanied by a decreasing microfibril angle and an increasing BD. As reported by Williamson and Wiemann (2010), the radial increase in BD concentrates denser wood at greater distance from the neutral axis of the stem, resulting in a stronger stem made of a limited amount of material.

Indeed, our numerical simulations implying radial BD variation suggest a slight improvement in trunk stiffness in flexion and torsion compared to constant BD. Despite these observations, considering mechanical performance only, it is more efficient to build a large low-density stem than a denser smaller stem with the same investment cost (Larjavaara and Muller-Landau 2010). The occurrence of high BD can also be interpreted in terms of trunk maintenance. Larjavaara and Muller-Landau (2010) proposed that the main advantage of high $\mathrm{BD}$ is the reduction in the surface area of the trunk, thereby reducing trunk maintenance and bark construction costs. For a given construction cost, BD radial increases represent an efficient strategy which enables a trade-off between height growth and radial growth during early stages of development, while limiting maintenance costs and guaranteeing trunk stiffness at the mature stage.

\section{Variations in interlocked grain (IG) within the tree}

We observed IG formation in all B. guianensis individuals. This characteristic is observed in numerous other tropical trees (Kribs 1950) and has already been reported for several Amazonian tree species including Goupia glabra, Dipteryx odorata, Tabebuia sp. or Aspidosperma sp. (Cabrolier 2009). Like BD, in Bagassa guinanensis, IG is outstanding in its amplitude and is reproducible from tree to tree. Hernandez and Almeida (2003) and Cabrolier (2009), respectively, reported maximum angle deviations of $16.4^{\circ}$ in Amburana cearensis and $15.8^{\circ}$ in Goupia glabra, whereas we measured almost the double in $B$. guianensis, with a maximum angle deviation of $31^{\circ}$. It should also be noted that extreme values depend on the size of the sampled trees and could be even larger in older trees. Another remarkable characteristic of the radial pattern of IG in B. guianensis is that variations in fibre orientation from pith to bark fit a sinusoidal model of constant parameters, despite the fact that the trees differed in their age and in the site where they were sampled. It is interesting to note that, in an eccentric disk sampled below the fork of one tree, we observed the same number of IG periods on each side of the pith despite different distances from pith to bark. This observation suggests that the control of the grain angle in IG in the cambium is more or less synchronous all around the disk.

IG has been mainly studied as it affects technological properties of wood products (Weddell 1961; Marsoem and Kikata 1987; Hernandez and Almeida 2003). Regarding the 
effect of IG on properties at sample scale, we observed an average loss of $0.44 \mathrm{GPa}$ of $\mathrm{MOE}$ ( $2.2 \%$ decrease per degree) for an increase of $1^{\circ}$ in GA. This result is consistent with the values reported by Cabrolier (2009) and Brémaud et al. (2010) ( -0.45 and $-0.5 \mathrm{GPa}$, respectively). It is important here to remind that consequences of IG at the tree scale are difficultly accessible. Indeed, large grain angle variations are only observable in mature tree having dimensions not adapted for experiments. Therefore, we observed properties at sample scale but these ex situ measurements must be analysed with caution, since they do not fully figure the behaviour at higher scale.

We used a numerical approach to simulate the impact of IG variation on tree biomechanics. The results of our model revealed that IG greatly improves torsional stiffness (increase of $+35 \%$ compared to axial grain, in the case of variable $\mathrm{BD})$. In the literature, much concern has been given to analyse bending forces by wind on trees, using different shape models, but little attention has been given to another type of mechanical loading like torsion. In the case of $B$. guianensis, its specific fibre network is an adaptive solution that intends to withstand the torsion induced by its particular architecture. Indeed, while symmetric trees are most likely subjected to bending loads when exposed to wind, asymmetric crowns induce different wind sail areas between the two sides of the stem. The latter result in strong twisting forces at the place of the fork that have been shown to be positively correlated to the degree of asymmetry and slenderness of the crown, subjecting the stem to a significant torque (Skatter and Kucera 1997, 1998, 2000). In $B$. guianensis, the crown is particularly slender and asymmetric. When reaching its mature form, it is characterised by a particular funnel morphology, exhibiting two main parts ("Y"-like shape, see Fig. 7f). This form stands out among the usual hemispheric crown shape observed in most tropical trees, like Dicorynia guianensis (Lehnebach et al. 2017) and Parkia velutina (Morel et al. 2018). This final shape is even more asymmetric than the models proposed by Skatter and Kucera (1997) and over exposes the crown to wind, transferring strong torsional loading from the fork to the trunk. This loading situation requires a strong torsional stiffness in addition to a sufficient bending stiffness.

As an answer to the torsion loading, Skatter and Kucera (1998) proposed that grain angle variations could be a growth strategy to ensure survival of the trees. The authors suggest that spiral grain in the outermost layers of mature pine trees could be a strategy to withstand torque. Here, our results show that IG is also an efficient adaptive mechanism improving trees' torsional stiffness but, contrary to spiral grain, it also enable maintaining most of the compressive and flexural stiffness.

Our results also highlight an improvement in wood tenacity with an increase in IG. The positive correlation between
IGindex and the fracture energy shows that IG improves resistance to stem opening in the TL fracture plane. This specific orientation of fibres limits the risks of cracks at the place of the fork (in this study, we did not measure higher IG below the fork, but IG was very high all along the trunk; data not shown). This hypothesis was also proposed by Cabrolier (2009), who suggested that IG would be a good way for adult trees to prevent the risk of stem splitting. This risk is particularly high at the fork, as both main branches exert a bending moment on opposite sides of the stem. Recent work on Corylus avellana L. showed that there was more interlocked wood grain formation close to branch insertions than in other sampling locations, leading to a higher specific fracture energy in the central apex zone (Özden et al. 2017). Slater and Ennos (2015) also reported that tortuous wood grain patterns as interlocked grain can supply additional strength to junctions in hazel trees. The authors even suggested that "this mechanical arrangement should inform anatomical studies of junctions and may inform the design of manufactured Y-shaped components made from fibrous composite materials". It is likely that a similar mechanism is at work in B. guianensis.

These elements support the hypothesis that in B. guianensis, IG may represent an optimal organisation of fibres to limit splitting risks at the central axis of the fork on the one hand, and stem torsional failure risks on the other hand. Such a strategy is even more optimal since, theoretically, the establishment of IG does not generate additional construction cost for the tree. Our results showed that IG could provide structural support, resistance to torsion and prevent the occurrence of cracks without producing more wood, i.e. is a good strategy with low carbon cost to offset the risks taken by the species to quickly reach the canopy and to resist wind forces when the crown is developed. Many other tropical species present combined variations of BD and IG within the tree. Comparing such patterns with the species growth strategies could provide interesting new information. Based on the example of B. guianensis, we look forward to more studies to evaluate if IG can be proposed as a functional trait for future studies in biomechanics and ecology.

Author contribution statement JB: sampling, measurements, analysis, discussion of the results and writing of the manuscript. RL: part of the sampling, analysis, discussion of the results and writing of the manuscript. SC: analysis and discussion of the results. AR: analysis and discussion of the results. JB: design of the research project and discussion of the results. BC: design of the research project, discussion of the results and writing of the manuscript.

Acknowledgements The authors thank Eric Nicolini (CIRADAMAP) and Onoefé NGwete (CIRAD_ECOFOG) for their help in 
tree identification and field work and Yves Caraglio (CIRAD—AMAP) to share his knowledge on Bagassa guianensis architecture. This research project was financially supported by the Labex CEBA (ANR10-LABX-25-01), CNRS-INSIS and European Social Fund awards.

\section{Compliance with ethical standards}

Conflict of interest The authors declare that they have no conflict of interest.

\section{References}

Arets EJMM, Van der Hout P, Zagt RJ (2003) Responses of tree populations and forest composition to selective logging in Guyana. In: Steege $\mathrm{H}$ (ed) Long-term changes in tropical tree diversity. Studies from the Guiana Shield, Africa, Borneo and Melanesia, Tropenbos Series 22. Tropenbos International Wageningen, Wageningen, pp 95-115

Arostegui A (1982) Recopilacion y analisis de studios tecnologicos de maderas peruanas. FAO, Lima

Ashby MF, Easterling KE, Harrysson R, Maiti SK (1985) The fracture and toughness of woods. Proc Royal Soc A Math Phys Eng Sci 398(1815):261-280

Barnett JR, Bonham VA (2004) Cellulose microfibril angle in the cell wall of wood fibres. Biol Rev 79(2):461-472

Barthelemy D, Caraglio Y (2007) Plant architecture: a dynamic, multilevel and comprehensive approach to plant form, structure and ontogeny. Ann Bot 99:375-407

Bossu J, Beauchêne J, Estevez Y, Duplais C, Clair B (2016) New Insights on wood dimensional stability influenced by secondary metabolites: the case of a fast-growing tropical species Bagassa guianensis Aubl. PLoS One 11:e0150777. https://doi.org/10.1371/ journal.pone. 0150777

Brémaud I, Cabrolier P, Gril J, Clair B, Gérard J, Minato K, Bernard Thibaut B (2010) Identification of anisotropic vibrational properties of padauk wood with interlocked grain. Wood Sci Technol 44(3):355-367

Brémaud I, El Kaïm Y, Guibal D, Minato K, Thibaut B, Gril J (2012) Characterisation and categorisation of the diversity in viscoelastic vibrational properties between 98 wood types. Ann For Sci 69(3):373-386

Cabrolier P (2009) Is interlocked grain an adaptive trait for tropical tree species in rainforest. In: 6th Plant Biomechanics Conference, Cayenne

Détienne $\mathrm{P}$ (1979) Contrefil à rythme annuel dans les faro Daniellia $s p$. Bois\&Forêts des Tropiques 183:67-71

Falster DS, Westoby M (2005) Tradeoffs between height growth rate, stem persistence and maximum height among plant species in a post-fire succession. Oikos 111:57-66

Fimbel R, Sjaastad E (1994) Wood specific gravity variability in Ceiba pentandra. Wood Fiber Sci 26(1):91-96

Fournier M, Dlouhá J, Jaouen G, Almeras T (2013) Integrative biomechanics for tree ecology: beyond wood density and strength. J Exp Bot 64(15):4793-4815

Guitard D (1987) Mécanique du matériau bois et composites. Cépaduès (ed) 238p. ISBN 285481527

Hejnowicz Z, Romberger JA (1979) The common basis of wood grain figures is the systematically changing orientation of cambial fusiform cells. Wood Sci Technol 13(2):89-96

Hernandez RE, Almeida G (2003) Effects of wood density and interlocked grain on the shear strength of three Amazonian tropical hardwoods. Wood Fiber Sci 35(2):89-96
Hernandez RE, Restrepo G (1995) Natural variation in wood properties of Alnus acuminata H.B.K. grown in Colombia. Wood and Fiber Sci 27:41-48

Hietz P, Valencia R, Wright SJ (2013) Strong radial variation in wood density follows a uniform pattern in two neotropical rain forests. Funct Ecol 27:684-704

King DA, Davies SJ, NurSupardi MN, Tan S (2005) Tree growth is related to light interception and wood density in two mixed dipterocarp forests of Malaysia. Funct Ecol 19(3):445-453

Kollmann FFP, Côté WA (1968) Principles of wood science and technology. In: Solid wood. Springer, Berlin, $592 \mathrm{p}$

Krawczyszyn J, Romberger JA (1979) Cyclical cell length changes in wood in relation to storied structure and interlocked grain. Can J Bot 57(7):787-794

Kribs DA (1950) Commercial foreign woods on the American market, a manual to their structure, identification, uses and distribution. Dissertation, Tropical Wood Laboratory, State College, $241 \mathrm{pp}$

Lachenbruch B, Moore JR, Evans R (2011) Radial variation in wood structure and function in woody plants, and hypotheses for its occurrence. In: Meinzer F, Lachenbruch B, Dawson T (eds) Sizeand age-related changes in tree structure and function. Tree physiology, 4th edn. Springer, Dordrecht

Larjavaara M, Muller-Landau HC (2010) Rethinking the value of high wood density. Funct Ecol 24(4):701-705

Lehnebach R, Morel H, Bossu J, Le Moguédec G, Amusant N, Beauchêne J, Nicolini E (2017) Heartwood/sapwood profile and the tradeoff between trunk and crown increment in a natural forest: the case study of a tropical tree (Dicorynia guianensis Amsh., Fabaceae). Trees Struct Funct 33(1):199-214. https://doi. org/10.1007/s00468-016-1473-7

Li X, Wu H, Southerton S (2011) Transcriptome profiling of Pinus Radiata juvenile wood with contrasting stiffness identifies putative candidate genes involved in microfibril orientation and cell wall mechanics. BMC Genom 12(1):480

Marsoem SN, Kikata Y (1987) The effect of interlocked grain on the mechanical properties of white meranti. Bull Nagoya Univ 9:51-77

McLean JP, Zhang T, Bardet S, Beauchêne J, Thibaut A, Clair B, Thibaut B (2011) The decreasing radial wood stiffness pattern of some tropical trees growing in the primary forest is reversed and increases when they are grown in a plantation. Ann For Sci 68(4):681-688

Montero C, Clair B, Alméras T, Van der Lee A, Gril J (2012) Relationship between wood elastic strain under bending and cellulose crystal strain. Compos Sci Technol 72(2):175-181

Morel H, Nicolini É, Bossu J, Blanc L, Beauchêne J (2017) Qualité et usages du bois de cinq espèces forestières adaptées à la plantation à vocation de bois d'oeuvre et testées en Guyane française. Bois\&Forêts des Tropiques 334:61-74. https://doi.org/10.19182 /bft2017.334.a31492

Morel H, Lehnebach R, Cigna J, Ruelle J, Nicolini E, Beauchene J (2018) Basic wood density variations of Parkia velutina Benoist, a long-lived heliophilic tree of Neotropical rainforest. Bois \& Forêts des Tropiques 335(1):59-69

Muller-Landau HC (2004) Interspecific and inter-site variation in wood specific gravity of tropical trees. Biotropica 36(1):20-32

Nicolini E, Beauchêne J, Leudet de la Vallée B, Ruelle J, Mangenet T, Heuret P (2012) Dating branch growth units in a tropical tree using morphological and anatomical markers: the case of Parkia velutina Benoist (Mimosoïdeae). Ann For Sci 69(5):543-555

Omolodun OO, Cutter BE, Krause GF, McGinnes EA (1991) Wood quality in Hildegardia barteri (Mast.) Kossern-an African tropical pioneer species. Wood Fiber Sci 23(3):419-435 
Osazuwa-Peters OL, Wright SJ, Zanne AE (2014) Radial variation in wood specific gravity of tropical tree species differing in growthmortality strategies. Am J Bot 101:803-811

Özden S, Slater D, Ennos R (2017) Fracture properties of green wood formed within the forks of hazel (Corylus avellana L.). Trees 31:903. https://doi.org/10.1007/s00468-016-1516-0

Parolin P (2002) Radial gradients in wood specific gravity in trees of central Amazonian floodplains. IAWA J 23(4):449-457

Schneider CA, Rasband WS, Eliceiri KW (2012) Nih image to imagej: 25 years of image analysis. Nat Methods 9:671-675

Skatter S, Kucera B (1997) Spiral grain - an adaptation of trees to withstand stem breakage caused by wind-induced torsion. Holz als Roh-und Werkstoff 55(2-4):207-213

Skatter S, Kucera B (1998) The cause of the prevalent directions of the spiral grain patterns in conifers. Trees 12(5):265-273

Skatter S, Kucera B (2000) Tree breakage from torsional wind loading due to crown asymmetry. For Ecol Manag 135(1-3):97-103

Slater D, Ennos R (2015) Interlocking wood grain patterns provide improved wood strength properties in forks of hazel (Corylus avellana L.). Arboricult J Int J Urban For 37(1):21-32

Thinley C, Palmer G, Vanclay J et al (2005) Spiral and interlocking grain in Eucalyptus dunnii. Holz Roh Werkst 63:372. https://doi. org/10.1007/s00107-005-0011-x

Webb CD (1969) Variation of interlocked grain in sweetgum (Liquidambar styracifula). For Prod J 19(8):45-48

Weddell E (1961) Influence of interlocked grain on the bending strength of timber, with particular reference to utile and greenheart. J Inst Wood Sci 7:56-72
Whitmore JL (1973) Wood density variation in Costa Rican balsa. Wood Sci 5(3):223-229

Wiemann MC, Williamson GB (1988) Extreme radial changes in wood specific gravity in some tropical pioneers. Wood Fiber Sci 20(3):344-349

Wiemann MC, Williamson GB (1989) Radial gradients in the specific gravity of wood in some tropical and temperate trees. For Sci 35(1):197-210

Williamson GB, Wiemann MC (2010) Age-dependent radial increases in wood specific gravity of tropical pioneers in Costa Rica. Biotropica 42(5):590-597

Williamson GB, Wiemann MC, Geaghan JP (2012) Radial wood allocation in Schizolobium parahyba. Am J Bot 99(6):1010-1019

Włoch W, Jura-Morawiec J, Kojs P, Iqbal M, Krawczyszyn J (2009) Does intrusive growth of fusiform initials really contribute to circumferential growth of vascular cambium? Botany 87(2):154-163

Woodcock DW, Shier AD (2002) Wood specific gravity and its radial variations: the many ways to make a tree. Trees 16:437-443

Yamamoto H, Sassus F, Ninomiya M, Gril J (2001) A model of anisotropic swelling and shrinking process of wood. Wood Sci Technol 35(1-2):167-181

Yao J (1970) Influence of growth rate on specific gravity and other selected properties of loblolly pine. Wood Sci Technol 4(3):163-175 